\title{
Research on destruction of oil-containing emulsion waste by hard solid demulsinators based on industry waste
}

\author{
Galina Tarasova ${ }^{1 *}$ and E. Grigoryeva ${ }^{1}$ \\ ${ }^{1}$ Belgorod State Technological University named after V.G. Shukhov, 308012, Belgorod, Russia
}

\begin{abstract}
The article presents experimental data on the destruction of oilcontaining emulsion effluents stabilized by solid emulsifiers, that were obtained by heat treatment of ore mining and processing enterprises (GOK) waste and sugar industry. The comparative characteristics on purification of oil emulsion effluents by solid demulsifiers when passing through a filtration layer consisting of solid demulsifiers particles and a layer of sand are given. As well as research into the practical application of oil sludge in the production of lightweight ceramic materials.
\end{abstract}

\section{Introduction}

Along with the problem of stable reverse emulsions formation, which is of great importance in many technical processes, the reverse problem is also important-the destruction of emulsions (demulsification) [1-4].

Demulsification is used in such common processes as separation of emulsified water from crude oil and tar, purification of condensate from oil, as well as in the purification of oil wastewater [5-10]. All methods of destruction can be divided into three groups: 1) mechanical or physical; 2) chemical; 3 ) electrical.

Currently, there are many demulsifiers used for the destruction of oil-containing emulsions. However, a demulsifier suitable for the destruction of one emulsion may be completely unusable for another. Therefore, the development and research of solid demulsifiers obtained on the basis of large-scale industrial waste is an urgent task.

It should be noted that the problem of destruction of oil emulsions in wastewater is no less urgent $[11,12]$. The purification technology of such effluents should ensure the complete destruction of the stable emulsion structure and the subsequent separation of the oil phase from the aqueous medium.

Therefore, the issues of affordable and high-quality wastewater treatment of metallurgical plants from oils and oil products is one of the priority areas of environmental protection. For wastewater treatment, sorption methods using active carbon and other sorbents (including those based on industrial waste), filters with granular loading, and others are widely used.

\footnotetext{
* Corresponding author: taga307@yandex.ru
} 


\section{Theoretical basis}

Demulsifiers are substances with a diphilic structure. Due to the property of diphilicity, demulsifiers are adsorbed on the interfacial boundary surface layers of dispersed phase particles, due to which the globules of water-oil emulsions reduce the interfacial tension and the destruction of natural stabilizers protective layer. The new layers formed, oriented around globules and consisting of demulsifier molecules, have almost no mechanical strength. Consequently, the fusion of the water dispersed phase particles is greatly facilitated, which leads to the subsequent destruction of the emulsion with a clear water and oil layers separation. Emulsions can be destroyed when passing through a filtration layer consisting of adsorption material and sand [9]. The essence of the filtering process through a granular loading layer is the separation of inhomogeneous systems consisting of a dispersion medium (liquid or gas) and solid particles or droplets suspended in it, which are produced in the filter. The emulsion is fed into the filter. Under the action of a pressure drop, the dispersion medium passes through the granular layer, and the particles of the dispersed phase are retained by the granular layer. In the filtering process, the channels of the granular layer become clogged with small particles of the dispersed phase and a sediment layer of increasing thickness is formed from large particles of the dispersed phase.

As a process result, the inhomogeneous system is divided into clarified dispersion medium and sludge. In granular filtration of oil-containing emulsions, the initial surface character of the loading grains is important. At a hydrophobic surface of grains particles adhesion is stronger, than at hydrophilic as on a surface of grains of hydrophilic materials there is a hydrate cover and adhesion of impurity drops occurs only where this cover is broken. The introduction of new technologies for the destruction of persistent oil-water emulsions requires the development of a science-based approach based on a thorough knowledge of the mechanism's formation structure of the interphase layer and the structural features of emulsifiers in the oil-water emulsions stabilization process

The main problem in the treatment of effluents containing petroleum products is the purification of emulsified petroleum products. The complexity of purification is a sufficiently high stability of such systems, which may be the result of the adsorption action of surfactants and the elastic protective layers formation or the electrolytes presence and the stabilizing effect strengthening of the DES layer. At all known methods efficiency of clearing of them is far from $100 \%$.

The purification process of oil wastewater on the granular loading layer is divided into two stages: delivery of droplets to the loading grains (contact with the grain surface and displacement of water from the grain surface by oil products) and filling narrow channels of the filter layer with oil products and moving along them in the filtration direction. When the emulsion is filtered, the internal loading space continuously changes as a result of oil sticking to the grains surface. The efficiency of water purification from undissolved petroleum products is determined, among other things, by the level of hydrophobicity of the granular loading, filter material properties (grain size, shape, surface roughness), layer geometric structure (layer porosity, grain homogeneity), filter layer height, and filtration rate. Quartz sand, crushed anthracite, foamed vermiculite, expanded clay, ceramic chips, thermolysis defecation (TD600) are used as filter materials [9] and others [6].

\section{Purpose and objects of research}

The aim of the work is to study the destruction of oil-containing emulsion effluents using solid demulsifiers and the use of spent oil sludge in the ceramic materials production. it is proposed to use GOK waste as demulsifiers - ferrous quartzite enrichment tailings (HOZHK) 
modified by heat treatment at a temperature of $600^{\circ} \mathrm{C}$, and for comparison, the known demulsifier - thermolysis defecation $\mathrm{TD}_{600}$.

HOZHK is a fine-grained powder from waste generated by dry and wet separation of crushed iron-containing quartzites [13]. The composition HOZHK includes up to $10 \%$ hematite and magnetite and about $72 \%$ silica. This is a fine powder with light gray color and an average particle size of 0,1 to $0,05 \mathrm{~mm}$. In accordance with the classification of harmful substances, this waste belongs to hazard class IV - low-hazard substances. Thermal activation of HOZHK is carried out in electric furnaces. The sample is placed in a special metal cell, and heat treated without oxygen at temperatures of $400-600^{\circ} \mathrm{C}$ [13].

Since the predominant part in the waste composition is silica, during heat treatment the structure of HOZHK becomes porous, with a very developed network of capillaries, which increases the adsorption properties, and, consequently, increases the degree of water purification. Defecation is a waste of sugar production, containing on its surface up to 18 $20 \%$ of various organic substances adsorbed as a result of sugar beet diffusion juice purification at the stages of saturation [14].

Thermolysis defecation $\left(\mathrm{TD}_{600}\right)$ is produced by heat treatment in electric furnaces or fluidized bed furnaces at low temperatures $\left(450-600^{\circ} \mathrm{C}\right)$ [15-19].

As a heat treatment result on the surface of the defecation there is incomplete combustion of organic substances and the charred substances formation, mainly consisting of carbon. A significant component of $\mathrm{TD}_{600}$ is calcium, magnesium carbonates, trace elements: silicon, potassium, sodium, nitrogen, phosphorus, toxic substances and heavy metal ions are absent.

\section{Materials and methods}

The oil-water emulsion containing insoluble impurities was purified in laboratory conditions using a plant consisting of a filter with a downward water flow and a purified water receiver, which is a cylindrical vessel of $4,5 \mathrm{~cm}$ in diameter with two openings (a two-layer filter with a granular charge). The resulting thermolysis defecation $\mathrm{TD}_{600}$ and Volsky sand were used as loading. As well as the obtained thermolysis HOZHK and Volsky sand. In laboratory conditions, was selected the optimal loading height, which was $7 \mathrm{~cm}$, and the optimal layer ratio, which was 1: 1 .

\section{Results and discussion}

Comparative data on the efficiency of the proposed demulsifier (HOZHK) and thermolysis defecation $\left(\mathrm{TD}_{600}\right)$ wastewater treatment are given in table 1 . From the table 1 it follows that HOZHK proposed as a filter material has a high degree of purification from organic and suspended substances and is practically not inferior to $\mathrm{TD}_{600}$.

Since HOZHK thermolysis particles have a greater hydrophilicity than $\mathrm{TD}_{600}$ and the particles are much larger in size, this can explain the lower interaction of HOZHK particles with the oil phase and, therefore, a lower purification compared to thermolysis defecation.

Table 1. Comparative characteristics of the physico-chemical characteristics of the oil-water emulsion before and after filtration

\begin{tabular}{|c|c|c|c|c|c|c|}
\hline \multirow{2}{*}{$\begin{array}{c}\text { Filter } \\
\text { material }\end{array}$} & \multicolumn{2}{|c|}{$\mathrm{COD}, \mathrm{mgO} / \mathrm{dm}^{3}$} & \multirow{2}{*}{$\begin{array}{c}\text { COD } \\
\text { Cleaning }\end{array}$} & \multicolumn{2}{|c|}{$\begin{array}{c}\text { Suspended matter, } \\
\mathrm{mg} / \mathrm{dm}^{3}\end{array}$} & $\begin{array}{c}\text { Suspended } \\
\text { Cleaning }\end{array}$ \\
\cline { 2 - 3 } & $\begin{array}{c}\text { Source } \\
\text { water }\end{array}$ & $\begin{array}{c}\text { After } \\
\text { filtering }\end{array}$ & $\begin{array}{c}\text { Efficiency, } \\
\%\end{array}$ & $\begin{array}{c}\text { Source } \\
\text { water }\end{array}$ & $\begin{array}{c}\text { After } \\
\text { filtering }\end{array}$ & $\begin{array}{c}\text { Efficiency, } \\
\%\end{array}$ \\
\hline HOZHK & 5020 & 301.2 & 94 & 5250 & 210 & 96.5 \\
\hline TD $_{600}$ & 5020 & 140.56 & 97.2 & 5250 & 105 & 98 \\
\hline
\end{tabular}


For disposal of oil sludge formed during the filtration of a water-oil emulsion, the possibility of using it as a burnable additive in the ceramic materials production was investigated.

To determine the optimal conditions for the disposal of oil sludge, it was added to the clay mass before molding ceramic samples by plastic pressing. The molded products were fired at a temperature of $900^{\circ} \mathrm{C}$ for 90 minutes. The ceramic masses composition is presented in table. 2.

The obtained samples were subjected to physical and mechanical tests. The data of the studies are presented in table 3 .

From the table 3 it follows that with an increase in the percentage of oil sludge in ceramic samples, the average density (volume weight) decreases, and the true density (specific gravity) remains almost constant; the porosity increases and the strength of the products decreases.

Table 2. The ceramic masses composition

\begin{tabular}{|c|c|c|c|}
\hline $\begin{array}{c}\text { No } \\
\text { composition }\end{array}$ & $\begin{array}{c}\text { Clay, } \\
\%\end{array}$ & Oil sludge, $\%$ & $\begin{array}{c}\text { Water, } \\
\%\end{array}$ \\
\hline 1 & 100 & 0 & 20 \\
\hline 2 & 85 & 15 & 20 \\
\hline 3 & 75 & 25 & 20 \\
\hline 4 & 65 & 35 & 20 \\
\hline 5 & 50 & 50 & 20 \\
\hline
\end{tabular}

Note. The moisture content of oil sludge after filtration was $27 \% \mathrm{wt}$.

Table 3. Physico-chemical properties of the obtained samples

\begin{tabular}{|l|c|c|c|c|c|}
\hline \multirow{2}{*}{ Indicators } & \multicolumn{5}{c|}{ No composition (sample) } \\
\cline { 2 - 6 } & 1 & 2 & 3 & 4 & 5 \\
\hline Air shrinkage, \% & 1.21 & 1.75 & 1.86 & 2.24 & 2.72 \\
\hline Fire shrinkage, \% & 3.34 & 3.67 & 4.41 & 4.78 & 5.15 \\
\hline Average density, kg/m ${ }^{3}$ & 1420 & 1412 & 1386 & 1312 & 1279 \\
\hline True density, kg/m ${ }^{3}$ & 1950 & 1950 & 1950 & 1950 & 1950 \\
\hline Porosity, \% & 27.2 & 27.6 & 29.0 & 32.7 & 34.5 \\
\hline Water absorption, \% at & 16.51 & 17.92 & 18.4 & 19.73 & 21.6 \\
\hline $\begin{array}{l}\text { Limit strength } \\
\text { compression, MPa }\end{array}$ & 12.32 & 12.24 & 11.52 & 8.71 & 7.21 \\
\hline $\begin{array}{l}\text { Thermal conductivity, } \\
\text { W/m·K }\end{array}$ & 0.2167 & 0.2143 & 0.2105 & 0.2041 & 0.2015 \\
\hline
\end{tabular}

Based on the test results, graphs were constructed of the density and strength dependences of the products on the added amount of oil sludge (Fig. 1 and 2). 


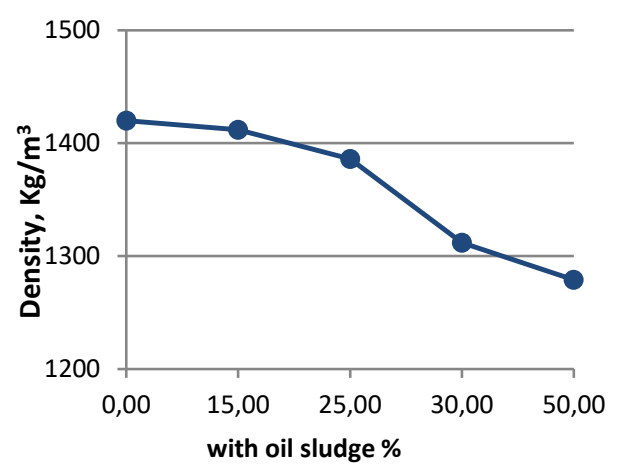

Fig. 1. The dependence of the obtained samples density on the content of oil sludge

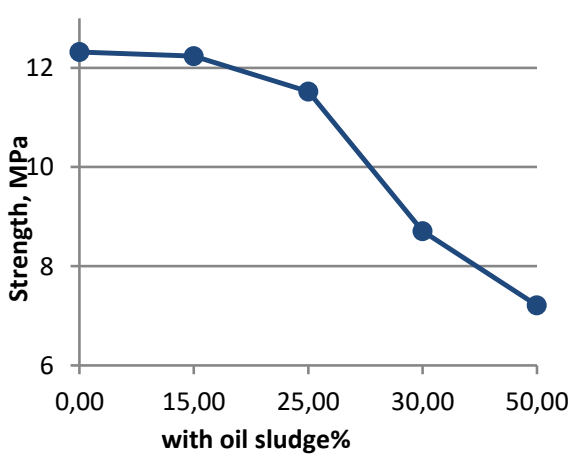

Fig. 2. The dependence of the obtained samples strength on the content of oil sludge

Fig. 1 and 2 shows that the optimum is the addition of oil sludge in an amount of $25 \%$ by raw materials weight, since a further increase in the waste content leads to a sharp decrease in these indicators.

Based on the results of experimental studies, it was possible to obtain building ceramic bricks with a density of $1455-1272 \mathrm{~kg} / \mathrm{m}^{3}$ and strength of $8,0-12,0 \mathrm{MPa}$, which, according to regulatory requirements, belongs to the effective class (GOST 530-2012 Ceramic brick and stone. General specifications)

Moreover, the use of oil sludge in the ceramic masses composition does not require special preliminary preparatory technological processes, and this contributes to the disposal of a significant amount of sludge generated during the water-oil emulsions filtration.

\section{Conclusion}

Thus, the proposed demulsifier (thermolysis HOZHK) can improve the quality of wastewater treatment by COD and almost completely remove suspended solids, as well as reduce the cleaning process cost through the use of large-scale production waste. In addition, the applied filter material will expand the raw material base, abandon scarce toxic materials. It is cheap, domestic, and its application can solve the environmental problem of the region in the utilization of technogenic waste from GOK.

The work is realized in the framework of the Program of flagship university development on the base of the Belgorod State Technological University named after V.G. Shukhov, using equipment of High Technology Center at BSTU named after V.G. Shukhov.

\section{References}

1. G.I. Tarasova, O.N. Shevaga, V.V. Tarasov, E.O. Gracheva, Investigation of inverse emulsions stabilized by thermolysis carbonate-containing waste, Monograph, Belgorod, 2016.

2. L.K. Mukhin, S.Ya. Shalyt, L.G. Ogneva, G.F. Milchakova, Investigation of the influence of structural and mechanical properties of mixed interfacial layers on the stability of inverse emulsions, Dispersed systems in drilling (Naukova Dumka, 1977).

3. S.S. Dukhin, New directions in the study of the double electric layer of dispersed particles, Advances in colloidal chemistry (Science, Moscow, 1973).

4. A.B. Taubman, A.F. Koretsky, Stabilization of emulsions with solid emulsifiers and 
coagulation structure formation, Advances in colloidal chemistry,1973.

5. B.V. Pokidko, D.A. Botin, M.Yu. Pletnev, Pickering emulsions and their use in the preparation of polymeric nanostructured materials, Bulletin of the Moscow Art Theater, 1, 3- 14 (2013).

6. Le Thanh Thanh, N.K. Zaitsev, N.B. Ferapontov, Features of separation of a stable oilwater emulsion on a coalescing filter with cellulose-based nozzles, doc IV international conference "Modern technologies for water treatment and protection of equipment from corrosion and scale formation", October 25-26, 2011, IEC “EXPOCENTER" (Moscow).

7. E.O. Gracheva, G.I. Tarasov, Wastewater treatment from oil-containing impurities by thermolysis clay, International Conference of Young Scientists "Current State and Environmental Quality of Individual Regions", Odessa, 2016, June 1-3, p. 77-79.

8. G.I. Tarasova, O.N. Shevaga, E.O. Gracheva, V.V. Tarasov, Investigation of the rheological and electrical properties of inverse emulsions stabilized by the thermolysis defect TD600, Bulletin of the University of Technology, 6, 90-93 (2015).

9. J.A. Sverguzova., G.I. Tarasova, S.V. Sverguzov, A. M. Blagodyrev, Pat. No. 2380137 of the Russian Federation, IPC B01D39 / 06. Filtration material for wastewater treatment, applicant and patent holder BSTU them. V.G. Shukhov; No. 20008142589/15; claimed 10/27/2008, publ. 01/27/2010. Bull. No. 3.

10. V. G. Babak, Highly concentrated emulsions. Physico-chemical principles of production and stability, The success of chemistry, 77 (8), 729-756 (2008).

11. G.I. Tarasova, A.M. Blagodyreva, The use of defecate waste from the sugar industry for the treatment of oily wastewater, Bulletin of BSTU named after V.G. Shukhov, 6, 128129 (2006).

12. N.A. Sobgaida, L.N. Olshanskaya, Yu.A. Makarova, Wastewater treatment of oil products by composite filters based on industrial wastes, Chemical and oil and gas engineering, 3, 37-41 (2010).

13. G.I. Tarasova, A rational method for producing filler pigments from metal-containing industrial wastes, Bulletin of BSTU named after V.G. Shukhov, 2, 128-132 (2012).

14. A.R. Sapronov, L.D. Bobrovnik, M. Sugar, Light and food industry, 1981.

15. G.I. Tarasova, Scientific basis and methodology for the integrated processing and disposal of calcium carbonate waste, Monograph, Belgorod. BSTU Publishing House, 2016.

16. G.I. Tarasova, The development of compositions of silicate-based paints thermalizing convejor-washing sediment - waste of the sugar industry, Construction Materials and Products, 1 (1), 21-31 (2018).

17. G.I. Tarasova, A rational method for producing filler pigments from metal-containing industrial wastes, Bulletin of BSTU named after V.G. Shukhov, 2, 128-132 (2012).

18. S.V. Sverguzova, G.I. Tarasova, I.V. Starostina, M. Y. Fedorina, Composite pigmentfiller on the basis of sludge of heat power plant and tails of engichment of ferruterous quartzites, Research Journal of Applied Sciences, 10 (12), 827-831 (2015).

19. G.I. Tarasova, I.V. Starostina, Special features of processing siliceous rocks, International Journal of Pharmacy and Technology, 8 (4), 24770-24780 (2016). 